\title{
PERSEPSI MAHASISWA TERHADAP INSTRUKTUR SEBAYA PADA PRAKTIKUM PENDENGARAN DI LABORATORIUM ILMU FAAL FAKULTAS KEDOKTERAN UNIVERSITAS GADJAH MADA
}

\author{
Gandhes Endah Pakarti, Widya Wasityastuti, Yayi Suryo Prabandari \\ Fakultas Kedokteran Universitas Gadjah Mada, Yogyakarta
}

\begin{abstract}
Background: The traditional learning method applies at Physiology Laboratory of Faculty of Medicine at Universitas Gadjah Mada (UGM) is considered ineffective for the lecturers in managing the students. Moreover, the students perceive that their needs are not adequately accommodated by the lecturers. This downside can be resolved by an alternative learning method which provides conducive, active, creative, effective and enjoyable learning environment called peer assisted learning method. This study is aimed at discovering the students' perceptions on peer assisted learning method and acquiring the students' feedback and expectations on the effectiveness of peer-teaching method implementation. Method: The study used cross-sectional design of descriptive research.

Results: From the questionnaire analysis with 150 respondents, 90 students of regularprogram and 60 students of international program, the result according to the frequencies of student perception were: 1) factor 1 were 45.8\% for very high category, 29.8\% for high category, 23.7\% for medium category, 0,8\% for very low category and $0 \%$ for low category; 2) factor 2 were $45 \%$ for high category, $41.2 \%$ formedium category, $11.5 \%$ for very high category, $1.5 \%$ for low category and $0.8 \%$ for very low category; 3 ) factor 3 were $51.9 \%$ for very high category, $31.3 \%$ for high category, $16.0 \%$ for medium category, $0.8 \%$ for very low category and $0 \%$ for low category; 4) factor 4 were $47.3 \%$ for high category, 31.3\% for very high category, $19.1 \%$ for medium category, $1.5 \%$ for low category and $0.8 \%$ for very low category. There was no difference in perception between the students of regular and international program. Responses to open questions and FGD show a variety of students'feedback and expectation on the peer assisted learning method.

Conclusion: The students have shown positiveperception on peer assisted learning as a learning method. The peer instructors required in implementing this model are thosestudents with good communication skill, confirmed academic qualification and capability in managing their fellowstudents'learning.
\end{abstract}

Keywords: perception, peer instructor, peer assisted learning, the Physiology Laboratory of Faculty of Medicine UGM

\begin{abstract}
ABSTRAK
Latar Belakang: metode pembelajaran tradisional yang masih diterapkan di Laboratorium Ilmu Faal Fakultas Kedokteran Universitas Gadjah Mada dirasa menyulitkan dosen dalam menguasai mahasiswa serta mahasiswa pun merasa kurang mendapat perhatian dari dosen. Di samping itu tersedia alternatif metode pembelajaran yang kondusif, aktif, kreatif, efektif, dan menyenangkan yaitu metode pembelajaran instruktur sebaya. Tujuan dari penelitian ini adalah untuk mengetahui persepsi mahasiswa terhadap metode instruktur sebaya serta mengetahui saran dan harapan mahasiswa terhadap instruktur sebaya tersebut.

Metode: menggunakan jenis penelitian deskriptif dengan rancangan potong-lintang/cross-sectional.

Hasil: berdasarkan analisis kuesioner pada 150 responden yang terdiri dari 90 mahasiswa program reguler dan 60 mahasiswa program internasional didapatkan frekuensi persepsi mahasiswa terhadap faktor 1 kategori sangat tinggi 45,8\%, tinggi 29,8\%, sedang 23,7\%, rendah $0 \%$, dan sangat rendah $0,8 \%$. Terhadap faktor 2 kategori tinggi $45 \%$, sedang $41,2 \%$, sangat tinggi $11,5 \%$, rendah $1,5 \%$, dan sangat rendah $0,8 \%$. Terhadap faktor 3 kategori sangat tinggi 51,9\%, tinggi 31,3\%, sedang $16,0 \%$, rendah $0 \%$, dan sangat rendah $0,8 \%$. Terhadap faktor 4 kategori tinggi $47,3 \%$, sangat tinggi $31,3 \%$, sedang $19,1 \%$, rendah $1,5 \%$, dan sangat rendah $0,8 \%$. Tidak terdapat perbedaan persepsi
\end{abstract}

Korespondensi: wasityastuti@yahoo.com 
antara mahasiswa program reguler dan internasional. Berdasarkan jawaban pertanyaan terbuka dan Focus Group Discussion didapatkan berbagai harapan dan saran mahasiswa terhadap model pembelajaran instruktur sebaya yang diujicobakan.

Kesimpulan: mahasiswa memberikan persepsi positif terhadap model pembelajaran instruktur sebaya. Instruktur sebaya yang diharapkan mahasiswa adalah yang pandai berkomunikasi, terstandarisasi secara akademik serta mampu mengarahkan mahasiswa.

Kata kunci: persepsi mahasiswa, instruktur sebaya, peer assisted learning, laboratorium Ilmu Faal FK UGM

\section{PENDAHULUAN}

Fakultas Kedokteran Universitas Gadjah Mada dilengkapi dengan sarana-prasarana penunjang dalam upaya mencetak tenaga medis yang kompeten. Sarana prasarana penunjang tersebut meliputi berbagai laboratorium praktikum, laboratorium keterampilan klinis, ruang-ruang diskusi tutorial, ruang-ruang kuliah, perpustakaan, dan lain sebagainya, masing-masing beserta alat-alat kelengkapannya. Salah satu dari sarana penunjang tersebut adalah laboratorium ilmu faal. Sejak pertama kali didirikan, Laboratorium Ilmu Faal Fakultas Kedokteran Universitas GadjahMada telah mengalami berbagai penyempurnaan, baik dalam sarana penunjang secara fisik maupun sumber daya manusia serta sistem di dalamnya. Hal tersebut ditujukan guna meningkatkan efektivitas pembelajaran mahasiswa.

Salah satu persoalan yang dikeluhkan oleh dosen dan mahasiswa saat ini adalah metode pembelajaran di Laboratorium Ilmu Faal yang masih menerapkan metode pembelajaran tradisional. Metode ini menerapkan 1 orang dosen mengajar untuk 1 ruang praktikum yang terdiri dari lebih kurang 40 mahasiswa. Hal ini dapat menyebabkan dosen mengalami kesulitan menguasai mahasiswa serta mahasiswa pun merasa kurang mendapatkan perhatian dari dosen.

Salah satu pendekatan pembelajaran yang diduga mampu mewujudkan situasi pembelajaran yang kondusif, aktif, kreatif, efektif, dan menyenangkan adalah pendekatan dengan metode instruktur sebaya. Model pembelajaran instruktur sebaya merupakan salah satu alternatif untuk mengubah metode pembelajaran tradisional. ${ }^{1,2}$ Model pembelajaran ini dapat diterapkan dalam berbagai konteks, seringkali digunakan sebagai penyokong metode pembelajaran tradisional atau kadang-kadang digunakan sebagai model pembelajaran alternatif. ${ }^{3,4}$

Wihardit ${ }^{5}$ menuliskan bahwa pengertian instruktur sebaya adalah seorang siswa pandai yang membantu belajar siswa lainnya dalam tingkat usia yang sama. Pada penelitian ini, instruktur sebaya merupakan kakak angkatan dari subjek penelitian yang mempunyai usia dalam rentang yang hampir sama (sebaya). Dalam hal tertentu,mahasiswa lebih paham dengan bahasa teman sebayanya daripada bahasa dosen.

Saat ini banyak universitas dan institusi perguruan tinggi telah mengadopsi model pembelajaran instruktur sebaya sebagai sistem pembelajaran untuk memfasilitasi pembelajaran mahasiswa. Hal ini terjadi di berbagai bidang, seperti akuntansi, ekonomi, ilmu alam, dan pendidikan dokter. ${ }^{6,7,89}$ Model pembelajaran instruktur sebaya telah lama dikenal dalam teori, penelitian, dan pendidikan klinis, sebagai sistem pendidikan yang berkualitas, yaitu mahasiswa, baik sebagai instruktur (tutor) maupun sebagai tutee mendapatkan manfaat dari pembelajaran..$^{10,11}$

Tujuan model pembelajaran ini bukanlah untuk mengulang informasi yang telah disampaikan dalam kuliah ataupun tutorial. Siswa akan memaparkan masalah dan topik yang ingin mereka pahami. Di sinilah peran instruktur, bertugas mendorong interaksi siswa, memfasilitasi kerja kelompok dan membangun pembelajaran aktif serta kemampuan penyelesaian masalah di antara siswa dalamkelompok tersebut. ${ }^{6,12}$ Model pembelajaran instruktur sebaya mendorong siswa menjadi lebih aktif dan mandiri dalam proses belajar. Teknik ini didefinisikan sebagai pendekatan pembelajaran mendalam (deep approach learning). ${ }^{13}$ 
Model pembelajaran instruktur sebaya memiliki banyak keuntungan. ${ }^{14}$ Keuntungan pertama adalah jarak usia yang dekat antara instruktur dan mahasiswa dapat memelihara proses pembelajaran karena adanya cognitive congruence (persamaan level kognitif). Kedua, mahasiswa merasa lebih nyaman dengan instruktur sebaya daripada dengan dosen, hal ini sesuai dengan teori social congruence (persamaan level sosial). Ketiga, instruktur sebaya memperoleh keuntungan karena adanya stimulasi proses pengolahan informasi tingkat tinggi yang terjadi pada proses persiapan dan saat pembelajaran. Keuntungan terakhir adalah instruktur sebaya dapat membangun kepercayaan diri dan meningkatkan motivasi dengan mengajar (role theory).

Persepsi didefinisikan sebagai proses kognitif yang kompleks melalui pandangan terhadap perbedaan antara kondisi yang dipandang dengan kondisi nyata. Dalam proses ini, individu memilih, mengatur, menyimpulkan, dan menarik suatu stimulus dan kondisi ke dalam gambaran yang berarti bagi mereka. ${ }^{15}$ Persepsi merupakan suatu proses yang didahului oleh proses penginderaan, yaitu proses diterimanya stimulus oleh individu melalui alat indera atau juga disebut proses sensoris. Proses tersebut kemudian diteruskan dan proses selanjutnya merupakan proses persepsi. ${ }^{16}$

Persepsi merupakan aktivitas yang terintegrasi dalam diri individu dan bersifat individual. Perasaan, kemampuan berpikir, pengalaman-pengalaman individu mempengaruhi persepsi seseorang. Perbedaan antar individu dalam mempersepsi suatu stimulus, menyebabkan hasil persepsi akan berbeda antara individu satu dengan individu lain. Menurut Walgito ${ }^{16}$, ada beberapa faktor yang mempengaruhi persepsi, objek yang dipersepsi, alat indera, syaraf, pusat susunan syaraf serta perhatian.

Persepsi terjadi melalui suatu proses, yaitu sebagai berikut:

1. Suatu objek atau sasaran menimbulkan stimulus, selanjutnya stimulus tersebut ditangkap oleh alat indera.

2. Stimulus suatu objek yang diterima oleh alat indera kemudian disalurkan ke otak melalui syaraf sensoris.
3. Otak selanjutnya memproses stimulus hingga individu menyadari objek yang diterima oleh alat inderanya. Dalam hal ini, terjadilah proses persepsi, yaitu suatu proses saat individu mengetahui dan menyadari suatu objek berdasarkan stimulus yang mengenai alat inderanya.

Penelitian ini bertujuan untuk mengetahui persepsi mahasiswa terhadap metode pembelajaran teman sebaya yang dilakukan pada praktikum pendengaran di Laboratorium Fisiologi, Fakultas Kedokteran, Universitas Gadjah Mada. Selain itu, bertujuan juga untuk mendapatkan umpan balik dan harapan mahasiswa terhadap proses pembelajaran teman sebaya.

\section{METODE}

Penelitian ini merupakan penelitian deskriptif dengan rancangan potong lintang.

Subjek penelitian ini adalah mahasiswa S-1 reguler dan internasional PSPD FK UGM angkatan 2010. Subjek penelitian terdiri dari 9 kelompok tutorial program reguler dan 6 kelompok tutorial program internasional. Jumlah total responden adalah 150 mahasiswa yang terdiri dari 90 mahasiswa program reguler dan 60 mahasiswa program internasional.

Instrumen yang digunakan dalam penelitian ini adalah kuesioner persepsi mahasiswa terhadap peer-assisted learning (instruktur sebaya) di Laboratorium Ilmu Faal FK UGM yang berisi pertanyaan-pertanyaan dengan pola jawaban menggunakan skala Likert 1-5 ( $1=$ sangat tidak setuju, $2=$ tidak setuju, $3=$ netral, $4=$ setuju, $5=$ sangat setuju) dan 4 pertanyaan terbuka mengenai pendapat dan harapan mahasiswa terhadap adanya instruktur sebaya di Laboratorium Ilmu Faal. Data yang ada diperdalam dengan focus group discussion (FGD).

Pernyataan-pernyataan dalam kuesioner disusun sesuai dengan tujuan penelitian didasarkan pada literatur dan penelitian-penelitian serupa yang telah dilakukan sebelumnya. Uji validitas dan reliabilitas kuesioner dilakukan dengan uji coba kuesioner pada 39 responden dengan 29 item kuesioner.

Setelah terbukti bahwa kuesioner valid dan reliabel, maka kuesioner dibagikan pada subjek penelitian yaitu mahasiswa yang mendapatkan pendampingan instruktur 
sebaya pada praktikum pendengaran di laboratorium Ilmu Faal FK UGM.

Analisis faktor diawali dengan kategorisasi persepsi mahasiswa didasarkan pada distribusi normal, sehingga didapatkan 5 kategori yaitu kategori sangat tinggi (persepsi sangat baik), kategori tinggi (persepsi baik), kategori sedang (bersikap netral), kategori rendah (persepsi buruk), dan kategori sangat rendah (persepsi sangat buruk). Kemudian dilakukan analisis faktor dengan menggunakan perangkat lunak statistik untuk mengelompokkan persepsi mahasiswa sesuai dengan kelompok faktor yang ditentukan.

Peserta FGD dipilih berdasarkan jawaban dari pertanyaan terbuka dalam kuesioner.

Analisis ini dilakukan untuk mengetahui frekuensi persepsi mahasiswa yang dikategorikan menjadi kategori sangat tingggi, kategori tinggi, kategori sedang, kategori rendah, dan kategori sangat rendah berdasarkan masingmasing faktor yang telah dikelompokkan dalam analisis faktor.

Uji normalitas dilakukan dengan Kolmogorov-Smirnov untuk mengetahui persebaran data yang didapatkan dari kuesioner.

Uji beda dengan menggunakan Independent t-test dilakukan untuk mengetahui adanya perbedaan persepsi antara mahasiswa program reguler dan mahasiswa program internasional berdasarkan pengelompokkan faktor-faktor.

\section{HASIL DAN PEMBAHASAN}

\section{Analisis Skala Likert Kuesioner}

Setelah dilakukan kategorisasi dan analisis faktor, didapatkan 4 kelompok faktor yaitu:

1. Faktor 1: penerimaan mahasiswa terhadap diadakannya peer-assisted learning (instruktur sebaya)

Penelitian mengenai instruktur sebaya baru pertama kali ini dilakukan di Laboratorium Ilmu Faal Fakultas Kedokteran Universitas Gadjah Mada yaitu pada praktikum pendengaran.
Berdasarkan kuesioner yang telah dianalisis didapatkan bahwa 60 (45,8\%) mahasiswa yang mengikuti penelitian ini mempunyai persepsi dengan kategori sangat tinggi (persepsi sangat baik) terhadap faktor 1 . Sedangkan 39 (29,8\%) mahasiswa mempunyai persepsi dengan kategori tinggi (persepsi baik),31 (23,7\%) mahasiswa mempunyai persepsi dengan kategori sedang (bersikap netral), hanya 1 mahasiswa $(0,8 \%)$ yangmempunyai persepsi dengan kategori sangat rendah (persepsi buruk), dan tidak ada satu pun (0\%) mahasiswa mempunyai persepsi dengan kategori rendah (persepsi sangat buruk).

Pada suatu penelitian dilaporkan $85 \%$ mahasiswa undergraduate bioscience Universitas Central Lanchashire UK mendapatkan pengalaman berharga/ dampak positif secara signifikan. ${ }^{8}$ Tanggapan positif juga dilaporkan oleh Atkins ${ }^{17}$ yang meneliti metode pembelajaran instruktur sebaya pada pembelajaran matematika di Universitas Kingston UK. Semua mahasiswa dalam penelitian tersebut dilaporkan merasa terbantu dalam mendapatkan hasil belajar yang lebih baik dan nilai yang tinggi dalam ujian.

Dengan demikian dapat diketahui bahwa sebagian besar mahasiswa dalam penelitian ini memberikan persepsi sangat baik terhadap faktor 1. Sehingga dapat dilaporkan bahwa dalam penelitian ini penerimaan mahasiswa terhadap diadakannya peer assisted learning (instruktur sebaya) adalah sangat baik. Hasil tersebut sesuai dengan hasil penelitian-penelitian serupa yang telah dilakukan sebelumnya. Hasil ini diperkuat dengan pernyataan-pernyataan mahasiswa yang tertulis dalam jawaban pertanyaan terbuka serta yang disampaikan melalui FGD.

2. Faktor 2: pengaruh peer-assisted learning (instruktur sebaya)

Berdasarkan hasil analisis kuesioner didapatkan bahwa $15(11,5 \%)$ mahasiswa mempunyai persepsi dengan kategori sangat tinggi (persepsi sangat baik) terhadap faktor 2 . Sedangkan 59 mahasiswa (45\%) mempunyai persepsi dengan kategori 
tinggi (persepsi baik), 54 (41,2\%) mahasiswa mempunyai persepsi dengan kategori sedang (bersikap netral), hanya $2(1,5 \%)$ mahasiswa mempunyai persepsi dengan kategori rendah (persepsi buruk), dan tersisa 1 mahasiswa $(0,8 \%)$ mempunyai persepsi dengan kategori sangat rendah (persepsi sangat buruk).

Dengan demikian diketahui bahwa mahasiswa memberikan persepsi/tanggapan positif pada pengaruh peer-assisted learning (instruktur sebaya) terhadap pelaksanaan praktikum dan minat mahasiswa. Hasil tersebut sesuai dengan literatur-literatur yang ada serta didukung dengan pernyataan-pernyataan mahasiswa yang tertulis dalam pertanyaan terbuka dan disampaikan melalui FGD.

Model pembelajaran instruktur sebaya dapat meningkatkan keuntungan sosial dan emosional, baik untuk mahasiswa maupun instruktur sebaya. Keuntungan sosial tersebut meliputi konsep diri positif, rasa percaya diri, ketertarikan dalam menjalin persahabatan dan koneksi di lingkungan kampus serta motivasi untuk belajar. ${ }^{7,8,18}$ Model pembelajaran instruktur sebayamendorong siswa menjadi lebih aktif dan mandiri dalam proses belajar. ${ }^{13}$ Demikianlah beberapa teori yang didapatkan dari penelitianpenelitian yang telah dilakukan sebelumnya. Teori tersebut menjadi dasar penelitian terhadap faktor 2 .

3. Faktor 3: kenyamanan mahasiswa terhadap keberadaan instruktur sebaya

Keuntungan yang dapat diperoleh melalui model pembelajaran instruktur sebaya adalah jarak yang dekat antara instruktur dan mahasiswa, adanya persamaan level sosial, sehingga mahasiswa merasa lebih nyaman dengan instruktur sebaya. ${ }^{14}$ Teori ini mendasari dilakukannya penelitian terhadap faktor 3 .

Dalam penelitian ini didapatkan hasil analisis kuesioner terhadap faktor 3 yangmenunjukkan bahwa 68 (51,9\%) mahasiswa mempunyai persepsi dengan kategori sangat tinggi (persepsi sangat baik), 41 (31.3\%) mahasiswa mempunyai persepsi dengan kategori tinggi (persepsi baik), $21(16 \%)$ mahasiswa mempunyai persepsi dengan kategori sedang (bersikap netral), sementara itu tidak ada satu pun (0\%) mahasiswa mempunyai persepsi dengan kategori rendah (persepsi buruk), dan hanya ada $1(0,8 \%)$ mahasiswa mempunyai persepsi dengan kategori sangat rendah (persepsi sangat buruk) terhadap faktor 3 .

Dengan demikian dapat dilaporkan bahwa mahasiswa memberikan tanggapan positif pada kenyamanan mahasiswa terhadap keberadaan instruktur sebaya dengan kata lain bahwa mahasiswa merasa nyaman dengan keberadaan instruktur sebaya. Hal ini sesuai dengan teori dan literatur yang ada serta didukung oleh pernyataan-pernyataan mahasiswa dalam jawaban pertanyaan terbuka serta yang disampaikan melalui FGD.

\section{Faktor 4: kemampuan instruktur sebaya}

Dalam penelitian ini dilakukan analisis kuesioner yang hasil analisisnya menunjukkan bahwa 41 $(31,3 \%)$ mahasiswa mempunyai persepsi dengan kategori sangat tinggi (persepsi sangat baik), 62 $(47,3 \%)$ mahasiswa mempunyai persepsi dengan kategori tinggi (persepsi baik), $25(19,1 \%)$ mahasiswa mempunyai persepsi dengan kategori sedang (bersikap netral), hanya ada 2 (1,5\%) mahasiswa yang mempunyai persepsi dengan kategori rendah (persepsi buruk), dan tersisa 1 $(0,8 \%)$ mahasiswa yang mempunyai persepsi dengan kategori sangat rendah (persepsi sangat buruk) terhadap faktor 4 .

Berdasarkan hasil tersebut diketahui bahwa mahasiswa mempunyai persepsi positif terhadap kemampuan instruktur sebaya. Hasil ini sesuai dengan teori dan literatur serta diperkuat dengan pernyataan mahasiswa dalam jawaban pertanyaan terbuka serta yang disampaikan dalam focus group discussion (FGD).

Instruktur berperan mendorong mahasiswa untuk bertanya serta berperan menjawab pertanyaan yang dianggap sulit tersebut. ${ }^{7,8,18}$ Selain itu instruktur sebaya bertugas mendorong interaksi mahasiswa, memfasilitasi kerja kelompok dan membangun pembelajaran aktif serta kemampuan penyelesaian masalah di antara mahasiswa dalam kelompok tersebut. ${ }^{6,12}$ Teori-teori tersebut menjadi dasar penelitian terhadap faktor 4 . 
Tabel 1. Frekuensi persepsi mahasiswa terhadap masing-masing faktor

Faktor 1 (penerimaan mahasiswa terhadap diadakannya peer assisted learning (instruktur sebaya))

\begin{tabular}{lcc} 
Kaltegori & Frekuensi & Persentase (\%) \\
\hline Sangat tinggi & 60 & 45,8 \\
Tinggi & 39 & 29,8 \\
Sedang & 31 & 23,7 \\
Rcndah & 0 & 0,0 \\
Sangat rendah & 1 & 0,8
\end{tabular}

Faktor 2 (Pengaruh peer assisted learning (instruktur sebaya) terhadap pelaksanaan praktikum dan minat mahasiswa)

\begin{tabular}{lcc} 
Kategori & Frekuensi & Persentase (\%) \\
\hline Sangat tinggi & 15 & 11,5 \\
Tinggi & 59 & 45,0 \\
Sedang & 54 & 41,2 \\
Rendah & 2 & 1,5 \\
Sangat rendah & 1 & 0,8
\end{tabular}

Faktor 3 (Kenyamanan mahasiswa terhadap keberadaan instruktur sebaya)

\begin{tabular}{ccc} 
Katcgori & Frckucnsi & Pcrscntasc (\%) \\
\hline Sangat tinggi & 68 & 51,9 \\
Tinggi & 41 & 31,3 \\
Sedang & 21 & 16,0 \\
Rendah & 0 & 0,0 \\
Sangat rendah & 1 & 0,8 \\
\hline Faktor 4 (Kemampuan instruktur sebaya) & \\
\hline Kategori & Frekuensi & Persentase (\%) \\
\hline Sangat tinggi & 41 & 31,3 \\
Tinggi & 62 & 47,3 \\
Sedang & 25 & 19,1 \\
Rendah & 2 & 1,5 \\
Sangal rendiah & 1 & 0,8 \\
\hline
\end{tabular}

Jawaban Pertanyaan Terbuka dan Focus Group Discussion (FGD)

Pertanyaan terbuka/ essay tidak dianalisis karena tes prestasi tipe karangan/ essay tidak memerlukan analisis item. ${ }^{19}$ Namun, pada penelitian ini jawaban pertanyaan terbuka dalam kuesioner digunakan untuk memperkuat/ mendukung hasil analisis kuesioner skala likert serta sebagai dasar pemilihanmahasiswa sebagai peserta FGD. Hasil yang diperoleh yaitu berupa pernyataan-pernyataan yang mendukung hasil analisis skala Likert serta harapan dan saran mahasiswa terhadap instrukrur sebaya.
Pernyataan-pernyataan mahasiswa yang mendukung hasil analisis skala Likert antara lain :

1. Faktor 1 - penerimaan mahasiswa terhadap diadakannya peer assisted learning (instruktur sebaya)

"Saya setuju dengan diadakannya instruktur sebaya, praktikum bisa lebih dimengerti dengan didampingi asisten, plus kadang diberi penjelasan klinisnya jadi makin menarik, jadi pengen tahu”. (1)

"Saya setuju, jika asisten diberikan secara berkelompok penjelasan akan lebih merata". (2) 
"Ya saya setuju, karena dari banyak faktor itu membantu sekali, bagi dosen, bagi asdosnya dan bagi mahasiswa. Soalnya bagi dosen, kerjanya ngga terlalu berat (misal dianggap berat). Bagi asdosnya banyak yang didapat, mulai dari ilmu, dll. Dan untuk mahasiswa, ada mahasiswa yang lebih seneng diajar asdos daripada dosen". (3)

"Dapat lebih membantu kami dalam memahami materi praktikum, lebih bisa mengerjakan soal-soal post tes". (4)

"Setuju. Agar mahasiswa lebih paham dan materinya lebih melekat di kepala". (5)

"Setuju, karena kadang dosen menjelaskan dengan bahasa yang terlalu tinggi". (6)

"Lebih jelas, dengan penyampaian bahasa yang mudah dimengerti, lebih simpel". (7)

"Lebih banyak bimbingan semasa praktikum, lebih memahami reasoning di balik prosedur". (8)

"Lebih seru soale, lebih bisa kuasai materi. Lebih memahami tujuan dari praktikum". (9)

"Setuju, kita jadi lebih up to date terhadap masalah-masalah klinis". (10)

2. Faktor 2 - pengaruh peer assisted learning (instruktur sebaya)

"Praktikum bisa lebih mudah dimengerti, diberi penjelasan klinis jadi makin menarik, jadi pengen tahu". (1)

"Jalannya praktikum menjadi lebih lancar...". (2)

"Praktikum dapat berjalan lancar dan serius, dapat membantu saya saat kesulitan dalam praktikum”. (3)

"Lebih enjoy, memotivasi saya untuk menjadi asdos faal". (4)

"...Saya lebih bersemangat mengikuti praktikum karena matlamat praktikum lebih jelas dan mudah dipahami" (5)

"Saya lebih bersemangat dalam proses praktikum karena jalannya praktikum lebih runtut dan terarah". (6)

“...Saya lebih percaya diri dalam praktikum”. (7)
"Kita jadi lebih up to date terhadap masalahmasalah klinis". (8)

"Instruktur sebaya memberikan informasi tambahan...”. (9)

"Lebih memacu keinginan siswa untuk memperdalam materi yang ada". (10)

“...korelasi klinis disampaikan juga”. (11)

3. Faktor 3 - kenyamanan mahasiswa terhadap keberadaan instruktur sebaya

"Mahasiswa dapat mengetahui tentang praktikum lebih detail, merasa tidak canggung untuk bertanya, dapat lebih berekspresi". (1)

"Lebih santai, lebih leluasa berdiskusi dan kalau ga ngerti tentang praktikum bisa langsung tanya". (2)

"Saya jadi lebih enak dalam memahami materi, karena mungkin umur saya dan asisten tidak jauh". (3)

"Penjelasannya lebih mudah dimengerti dan lebih mendapat perhatian (mengenai mengerti atau tidak mengerti terhadap materi) dan lebih mudah bertanya". (4)

"Apabila ada hal yang tidak diketahui, dapat langsung bertanya pada asisten. Asisten menjelaskan materi di waktu praktikum berlangsung jadi masih ingat materi buat bekal untuk post test". (5)

"Saya amat memahami penjelasan asisten mahasiswa, dan saya dapat menanyakan soalansoalan tanpa barrier". (6)

"Membantu untuk lebih memahami topik praktikum, lebih leluasa untuk bertanya/ minta diulang kalau ada yang kurang jelas". (7)

"Saya merasa nyaman dalam berinteraksi dan berdiskusi dengan asisten mahasiswa. Dalam bertanya lebih tidak canggung". (8)

"Saya lebih bisa mengerjakan post test...". (9)

"Saya lebih mengerti, kalau dosen neranginnya cepet banget, bahasanya beda". (10) 
4. Faktor 4 - kemampuan instruktur sebaya

"Saya merasa lebih diperhatikan dan terbimbing". (1)

"Asisten mahasiswa dapat menerangkan ilmu faal dengan bagus kepada kami”. (2)

"Lebih diarahkan dalam praktikum,...". (3)

"Bisa menjelaskan topik praktikum dengan baik dan tidak terburu-buru". (4)

"Dapat membimbing, nilai post test bagus, banyak hal baru yang didapat". (5)

"Lebih mudah bertanya, lebih terbimbing". (6)

"Mengerti topik, bisa menjelaskan, membantu menerangkan pada mahasiswa". (7)

"Bisa memberikan penjelasan tentang jawaban pre test dan post test yang benar dan mendiskusikannya". (8)

Harapan dan saran mahasiswa terhadap peer assisted learning (instruktur sebaya) antara lain sebagai berikut :

1. Instruktur sebaya harus pintar berkomunikasi.

2. Instruktur sebaya terstandarisasi secara kompetensi akademik.

3. Instruktur sebaya mampu dan mau antusias mengarahkan mahasiswa dalam praktikum.

4. Instruktur sebaya mampu menghubungkan antara topik praktikum dan kasus sehari-hari.

5. Instruktur sebaya tidak bersikap menggurui mahasiswa.

6. Mahasiswa menyarankan segera diadakannya peer assisted learning (instruktur sebaya) untuk praktikum-praktikum selanjutnya di Laboratorium Ilmu Faal FK UGM.

7. Mahasiswa menyarankan agar dalam model pembelajaran instruktur sebaya dikemudian hari dosen tetap menyampaikan materi singkat di awal praktikum dengan kehadiran instruktur sebaya, kemudian instruktur sebaya mendampingi mahasiswa dalam melakukan praktikum serta memberikan penjelasan yang terlewatkan oleh dosen (tanpa mengulang materi yang telah disampaikan dosen).

8. Mahasiswa berharap agar instruktur sebaya dapat menjelaskan clinical reasoning dan dasar-dasar ilmu faal di balik prosedur praktikum serta mampu menghubungkannya dengan kasus-kasus dalam kehidupan sehari-hari.

Uji Beda Persepsi Mahasiswa Program Reguler dan Internasional terhadap Instruktur Sebaya

Berdasarkan hasil uji beda dengan Independent T-test menggunakan software SPSS 16 diketahui bahwa nilai $\mathrm{P}>0,05$, hal ini menunjukkan bahwa tidak ada perbedaan persepsi yang signifikan antara mahasiswa program reguler dan program internasional terhadap instruktur sebaya dilihat dari keempet faktor yang diteliti. Baik mahasiswa program reguler maupun internasional memberikan persepsi/ tanggapan positif terhadap instruktur sebaya,hal tersebut didukung oleh pernyataan-pernyataan mahasiswa yang tercantum pada jawaban pertanyaan terbuka serta disampaikan melalui FGD.

\section{KESIMPULAN}

Berdasarkan analisis kuesioner, jawaban pertanyaan terbuka dan hasil focus group discussion (FGD) dapat disimpulkan beberapa hal sebagai berikut:

1. Mahasiswa baik program reguler maupun internasional angkatan 2010 yang mengikuti praktikum pendengaran dengan pendampingan instruktur sebaya memberikan persepsi positif terhadap model pembelajaran instruktur sebaya tersebut dinilai berdasarkan keempat faktor yang diteliti.

2. Instruktur sebaya yang diharapkan mahasiswa adalah instruktur yang pandai berkomunikasi, terstandarisasi secara akademik serta mampu mengarahkan mahasiswa.

3. Mahasiswa dalam penelitian ini menyarankan diadakannya model pembelajaran instruktur sebaya untuk praktikum-praktikum selanjutnya dengan sedikit modifikasi pada tahapantahapannya.

\section{UCAPAN TERIMA KASIH}

Ucapan terima kasih kepada seluruh Staf Bagian Ilmu Faal Fakultas Kedokteran Universitas Gadjah Mada, Staf Bagian Parasitologi Fakultas Kedokteran Universitas Gadjah Mada, dan semua pihak yang telah membantu jalannya penelitian hingga penelitian ini dapat terselesaikan dengan baik. 
Tabel 2. Perbandingan persepsi mahasiswa program reguler dan internasional terhadap masing-masing faktor

Faktor 1 ( penerimaan mahasiswa terhadap diadakannya peer assisted learning (instruktur sebaya) )

\begin{tabular}{lrr} 
Kategori & Reguler & Internasional \\
\hline Sangat tinggi & $38(46,3 \%)$ & $22(44,9 \%)$ \\
Tinggi & $27(19,5 \%)$ & $12(30,6 \%)$ \\
Sedang & $16(14,5 \%)$ & $15(24,5 \%)$ \\
Rendah & $0(0,0 \%)$ & $0(0,0 \%)$ \\
Sangat rendah & $1(1,2 \%)$ & $0(0,0 \%)$
\end{tabular}

Faktor 2 (Pengaruh peer assisted learning (instruktur sebaya) terhadap pelaksanaan praktikum dan minat mahasiswa)

$\begin{array}{lrr}\text { Sangat tinggi } & 8(9,8 \%) & 7(14,3 \%) \\ \text { Tinggi } & 39(47,8 \%) & 20(42,9 \%) \\ \text { Sedang } & 33(40,2 \%) & 21(40,8 \%) \\ \text { Rendah } & 1(1,2 \%) & 1(2,0 \%) \\ \text { Sangat rendah } & 1(1,2 \%) & 0(0,0 \%)\end{array}$

Faktor 3 (Kenyamanan mahasiswa tcrhadap kcbcradaan instruktur scbaya)

$\begin{array}{lrr}\text { Sangat tinggi } & 45(54,9 \%) & 23(46,9 \%) \\ \text { Tinggi } & 24(29,3 \%) & 17(34,7 \%) \\ \text { Sedang } & 12(14,6 \%) & 9(18,4 \%) \\ \text { Rendah } & 0(0,0 \%) & 0(0,0 \%) \\ \text { Sangat rendah } & 1(1,2 \%) & 0(0,0 \%)\end{array}$

\begin{tabular}{crr} 
Faktor 4 (Kemampuan instruktur sebaya ) & \\
Sangat tinggi & $25(30,5 \%)$ & $16(32,7 \%)$ \\
Tinggi & $37(45,1 \%)$ & $25(51,0 \%)$ \\
Sedang & $18(22,0 \%)$ & $7(14,3 \%)$ \\
Rendah & $1(1,2 \%)$ & $1(2,0 \%)$ \\
Sangat rendah & $1(1,2 \%)$ & $0(0,0 \%)$ \\
\hline
\end{tabular}

\section{DAFTAR PUSTAKA}

1. Beardon T. Peer assisted learning and raising standards. In: Goodlad S, editor. Students as tutors and mentors. London: Kogan Page; 1995.

2. Goodlad S. Students as tutors and mentors. London: Kogan Page; 1995.

3. Fisher P and Howse, J. Responding to student needs in New Zealand Polytechnic and Secondary Schools. In:Goodlad S, editor. Students as tutors and mentors. London: Kogan Page; 1995.

4. Moody S, McCrae J. Cross year pear tutoring with law undergraduates. In: Foot HC, editor. Group and interactive learning Southampton. Computational Mechanics Publications; 1994.

5. Djalil A. Metode penelitian. Jakarta: Universitas Terbuka; 1997.

6. O'Donnell R. Introducing peer-assisted learning in first year accounting in Australia. Macquarie Economics
Research Papers 12; 2004. [cited 2008 January 15]. Available from: http://www.econ.mq.edu.au/research/ 2004/ PALDec04.pdf

7. Morrision K. Peer assisted study sessions: supporting quality learning \& student engagement in economics \& business. Synergy. 2007;24:3-7.

8. Tariq VN. Introduction and evaluation of peer-assisted learning in first year undergraduate bioscience. Bioscience Education e-Journal; 2005. [cited 2008 January 30]. Available from:http://www.bioscience. heacademy.ac.uk/journal/vol6/beej-6-3.

9. Howman M, Bertfield D, Needleman S. The PAL project: peer-assisted learning in medicine. [Internet]. 2002. [cited 2008 Jan 30]. Available from: http:// www.ucl.ac.uk/acme/The\%20PAL\%20Project.doc

10. Aviram M, Ophir R, Raviv D, Shiloah M. Experiential learning of clinical skills by beginning nursing students: "coaching" project by fourth-year student interns. J Nurs Educ. 1998;37:228-31. 
11. Topping K. Peer-assisted learning: a practical guide for teachers. Newton, MA: Brookline Books; 2001.

12. Congos D, Schoeps N. Does supplemental instruction really work and what is it anyway? Studies in Higher Education.1993;18:1-13.

13. Biggs J. What do inventories of students' learning process really measure? a theoretical review and clarification. British Journal of Educational Psychology. 1993;83:3-19.

14. Cate OT, Steven D. Dimensions and psychology of peer teaching in medical education.Medical Teacher. 2007;29:546-52.

15. Luthans F. Self-efficacy and work-related performance: a meta-analysis. Psychological Bulletin. 1998(a); 124(2):240-61.
16. Walgito B. Pengantar psikologi umum. Andi: Yogyakarta; 2002.

17. Atkins N, May S, Marks-Marden D. Widening participation in subjects requiring data handling skills: the mathsaid project. Journal of Further and Higher Education. 2005;29(4):353-65.

18. Dobbie M, Joyce S. Peer-assisted learning in accounting: a qualitative assessment. Asian Social Science. 2008;4(3):18-25.

19. Azwar S. Validitas dan reliabilitas. Yogyakarta: Pustaka Pelajar; 1997. 